\title{
SUPERENDIVIDAMENTO DO CONSUMIDOR NA PANDEMIA: ANÁLISE CRÍTICA DO PROJETO DE LEI DO SENADO SOBRE A LIMITAÇÁO DE JUROS DO CARTÁO DE CRÉDITO E CHEQUE ESPECIAL
}

\author{
CONSUMER OVER-INDEBTENESS IN PANDEMIA: \\ ANALYSIS OF THE DRAFT SENATE LAW ON THE LIMITATION OF \\ INTEREST ON CREDIT CARDS AND OVERDRAFT IN PANDEMIA
}

PAUlO MÁrCiO REIS SANTOS ${ }^{1}$

Flávia GuimarâEs CAMPos PAUlino dA COSTA ${ }^{2}$

ROBERTA MACIEL CAMPOLINA ${ }^{3}$

\section{RESUMO}

O presente artigo tem por objetivo analisar o Projeto de Lei $n^{\circ} 1.166 / 20$, que prevê a limitação dos juros de cartões de crédito e cheque especial para atenuar os impactos financeiros durante a pandemia, analisados os aspectos materiais da proposta e o direito comparado. Como problema de pesquisa, indaga-se se o referido projeto dispõe de mecanismos eficientes para o enfrentamento do quadro de elevada complexidade, capazes de mitigar o superendividamento no Brasil, sobretudo no âmbito da economia das famílias mais vulneráveis, consideravelmente expostas no contexto da pandemia da COVID-19. A metodologia de pesquisa adotada foi documental e bibliográfica, mediante a análise de documentos especializados, constituída por livros e trabalhos científicos. No resultado, será destacada a importância da educação financeira aliada a estímulos positivos como instrumento para a redução do superendividamento do consumidor no Brasil.

Palavras-chave: Cartão de Crédito. Cheque Especial. Pandemia. Projeto de Lei do Senado. Superendividamento.

1 Professor no Programa de Mestrado e na Graduação em Direito da Universidade FUMEC. Coordenador do Setor de Pós- graduação Lato Sensu da Universidade FUMEC. Sócio fundador da PMRS Advocacia e Consultoria. Bacharel em Direito pela Universidade FUMEC (2003). Doutor (2019) e Mestre (2009) Faculdade de Direito da Universidade Federal de Minas Gerais (UFMG). Possui experiência docente e profissional em Direito da Concorrência e Inovação, Direito Econômico, Direito Internacional Privado e Relações de Consumo. ORCID iD: https://orcid.org/0000-0003-3279-8136. Lattes: http://lattes. cnpq.br/8117691847816487.E-mail: paulomarcio@fumec.br.

2 Mestranda em Direito no PPGD da FUMEC. ORCID iD: https://orcid.org/0000-0002-7205-146X . E-mail: fgcampos22@ yahoo.com.br.

3 Mestranda em Direito no PPGD da FUMEC. ORCID iD: https://orcid.org/0000-0002-7270-4109. E-mail: roberta.campolina@ hotmail.com.

Como citar esse artigo/How to cite this article:

SANTOS, Paulo Márcio Reis; COSTA, Flávia Guimarães Campos Paulino da; CAMPOLINA, Roberta Maciel. Superendividamento do consumidor na pandemia: análise crítica do projeto de lei do Senado sobre a limitação de juros do cartão de crédito e cheque especial. Revista Meritum, Belo Horizonte, vol. 15, n. 2, p. 308-320, Maio/Ago. 2020. DOl: https://doi.org/10.46560/meritum. v15i2.8267. 


\section{ABSTRACT}

The purpose of this article is to analyze Bill $n^{\circ} 1,166 / 20$, which provides for the limitation of interest on credit cards and overdraft to mitigate financial impacts during the pandemic, analyzing the material aspects of the proposal and the right compared. As a research problem, it is asked whether the referred bill has efficient mechanisms to face the highly complex situation, capable of mitigating over-indebtedness in Brazil, especially in the context of the economy of the most vulnerable families, considerably exposed in the context of the the COVID-19 pandemic. The research methodology adopted was documentary and bibliographic, through the analysis of specialized documents, consisting of books and scientific works. In the result, the importance of financial education combined with positive stimuli as an instrument for reducing consumer over-indebtedness in Brazil will be highlighted.

Keywords: Credit card. Overdraft. Pandemic. Over-indebtedness. Senate Bill.

\section{INTRODUÇÃO}

Com o acesso ao crédito fácil trazido por diversas alternativas de pagamentos e o controle da inflação, nota-se que, independente das taxas de juros aplicadas, é usual a utilização do crédito em suas inúmeras modalidades para pagamento de despesas.

Essa facilidade de acesso ao crédito trouxe benefícios para que a qualidade de vida pudesse ser melhorada. No entanto, houve o incremento da taxa de juros para compensar o cedente pelo valor do capital disponibilizado ao consumidor.

Quando a obrigação contraída não consegue ser honrada no seu devido tempo, cria-se o círculo vicioso de endividamento do consumidor. No Brasil isso é reforçado pela percepção acerca da ausência de orientação e educação financeira. Esse cenário, aliado ao consumismo exacerbado, cada vez mais atento ao "ter", representa um dos mais fortes motivos para haver mais de 67,4\% das famílias endividadas (ROUBICEK, 2020).

Diante disso, o Poder Executivo, em 9 de junho de 2020, para implementar a política de educação financeira, editou o Decreto $n^{\circ} 10.393$, que instituiu a nova Estratégia Nacional de Educação Financeira - ENEF e o Fórum Brasileiro de Educação Financeira - FBEF, para promover a educação financeira, securitária, previdenciária e fiscal no País (BRASIL, 2020).

A facilidade de obtenção de crédito, principalmente por meio do cartão de crédito e do cheque especial, fez a curva do endividamento apresentar tendência de alta nos últimos anos (BRASIL, 2020). No caso específico do cartão de crédito, a possibilidade de se ter um benefício sem o desembolso imediato para pagamento à vista faz com que o consumidor aproveite essa modalidade, em muitos casos, sem o devido planejamento e sustentabilidade na renda, ou seja, um gasto não projetado, mas realizado.

De acordo com a Confederação Nacional do Comércio de Bens, Serviços e Turismo (CNC), houve altas consecutivas de endividamento das famílias brasileiras no ano de 2019, encerrado com o maior índice desde 2013 (CONFEDERAÇÃO NACIONAL DO COMÉRCIO DE BENS, SERVIÇOS E TURISMO, 2020).

Acredita-se que o elevado cenário de endividamento poderá piorar em função das medidas de enfrentamento à COVID-19 tomadas pelo Poder Público no Brasil (BRASIL, 2020). Isso porque a busca do crédito foi a solução encontrada nesse novo contexto, na tentativa de 
atender demandas essenciais, como aluguel, luz elétrica, água, alimentação, dentre outras, quadro agravado diante de uma inadequada administração financeira das famílias brasileiras.

0 inadimplemento das obrigações creditícias em modalidades que apresentam altas taxas de juros elevam o nível de endividamento e criam uma conjuntura preocupante. As taxas de juros do cheque especial e do cartão de crédito no Brasil são uma das mais elevadas do mundo, ensejando necessárias medidas para a atenuação, especialmente em período tão excepcional, como o de uma pandemia.

O presente artigo tem como objetivo analisar o Projeto de Lei n 1.166 de 2020 (BRASIL, 2020), de autoria do Senador Álvaro Dias (Podemos), do Paraná, que prevê a limitação da taxa de juros para o cartão de crédito e cheque especial, como forma de atenuar os impactos negativos advindos da pandemia da COVID-19.

Como problema de pesquisa, indaga-se se o referido Projeto de Lei dispõe de mecanismos eficientes para o enfrentamento do quadro de elevada complexidade, capazes de mitigar o superendividamento no Brasil, sobretudo no âmbito da economia das famílias mais vulneráveis, consideravelmente expostas no contexto da pandemia da COVID-19.

A metodologia de pesquisa adotada foi documental e bibliográfica, mediante a análise de documentos especializados, constituída por livros e trabalhos científicos.

\section{EDUCAÇÃO FINANCEIRA E O PANORAMA DO SUPERENDIVIDAMENTO NO BRASIL NA ÚLTIMA DÉCADA}

A economia comportamental aponta que, diferentemente da visão da economia tradicional, as pessoas decidem com base em hábitos, experiências pessoais e regras práticas simplificadas. Aceitam soluções apenas satisfatórias, buscam rapidez, têm dificuldade em equilibrar interesses de curto e longo prazo e são muito influenciadas por fatores emocionais, inclusive pelo comportamento dos demais indivíduos (ÁVILA; BIANCHI, 2020).

A educação financeira, como proposta pelo governo, por meio do Decreto $n^{\circ} 10.393$, de 2020, aliada a estímulos positivos, tal como preconizam por Richard $\mathrm{H}$. Thaler e Cass Sunstein na figura metafórica do "arquiteto de escolhas" (THALER; SUNTEIN, 2020), pode representar a reorientação e o aprimoramento das escolhas domésticas e do gerenciamento financeiro, com capacidade de mitigar o quadro do superendividamento.

Thaler e Sunstein consideram que os indivíduos e instituições, mediante estímulos conscientes e invisíveis e com o mínimo de custo político e econômico, podem obter grandes conquistas em relação às finanças, saúde pública e igualdade. Para eles, os agentes empresariais, governos, pais, professores e médicos podem vir a ser "arquitetos de escolhas" (THALER; SUNSTEIN, 2020). ${ }^{4}$

4 Nudge é um conceito da ciência comportamental, teoria política e economia, que propõe estímulo positivo e sugestões indiretas como forma de influenciar o comportamento e a tomada de decisão de grupos ou indivíduos. Esse incentivo contrasta com outras maneiras de obter conformidade, como a educação, a legislação ou a imposição. 
Os avanços nas diversas vertentes do campo de estudo econômico-comportamental ocorrem de forma acelerada e seu amplo uso em diversas áreas temáticas, desde a academia ao setor público e privado, reforçam a importância da incorporação e consolidação de insights provenientes da economia comportamental diante das premissas econômicas tradicionais (RIBEIRO; DOMINGUES, 2018).

O crédito é uma fonte extra de recursos, oriundos de terceiros, representados por bancos, financeiras, cooperativas de crédito, dentre outros, que traz a oportunidade de aquisição de bens ou a contratação de serviços de maneira antecipada. Isso possibilita que a pessoa física ou jurídica complemente a sua renda para comprar algo que almeja.

A disseminação do crédito fácil à população, bem como o aumento de outras formas de pagamento está tornando a sociedade brasileira cada vez mais propícia ao consumo. Outro fator de aumento do grau de endividamento da família brasileira é a ausência de uma cultura de educação financeira e pela falta monitoramento da aplicação dos recursos financeiros a longo prazo.

A facilidade em se obter crédito no Brasil reforçado por essa falta de educação financeira faz com que o crédito configure um problema ao invés de uma solução, pois os juros, quando não considerados, acabam por criar uma sobrecarga no cumprimento da obrigação negociada. Isso leva muitas vezes o consumidor a buscar em um novo crédito como forma de pagamento do anterior, assim cria-se a figura do superendividamento (FANECO, 2016).

Esta realidade tem gerado um aumento significativo do endividamento das famílias conforme levantamento realizado pela Confederação Nacional do Comércio de Bens, Serviços e Turismo (CONFEDERAÇÃO NACIONAL DO COMÉRCIO DE BENS, SERVIÇOS E TURISMO, 2020).

De acordo com uma Pesquisa de Endividamento e Inadimplência do Consumidor (PEIC) realizada em julho de 2020, o número de famílias brasileiras com dívidas atingiu o nível de 67,4\%, alcançando o maior índice percentual desde 2010.

\section{Gráfico 1}

\section{RECORDE DA SÉRIE}

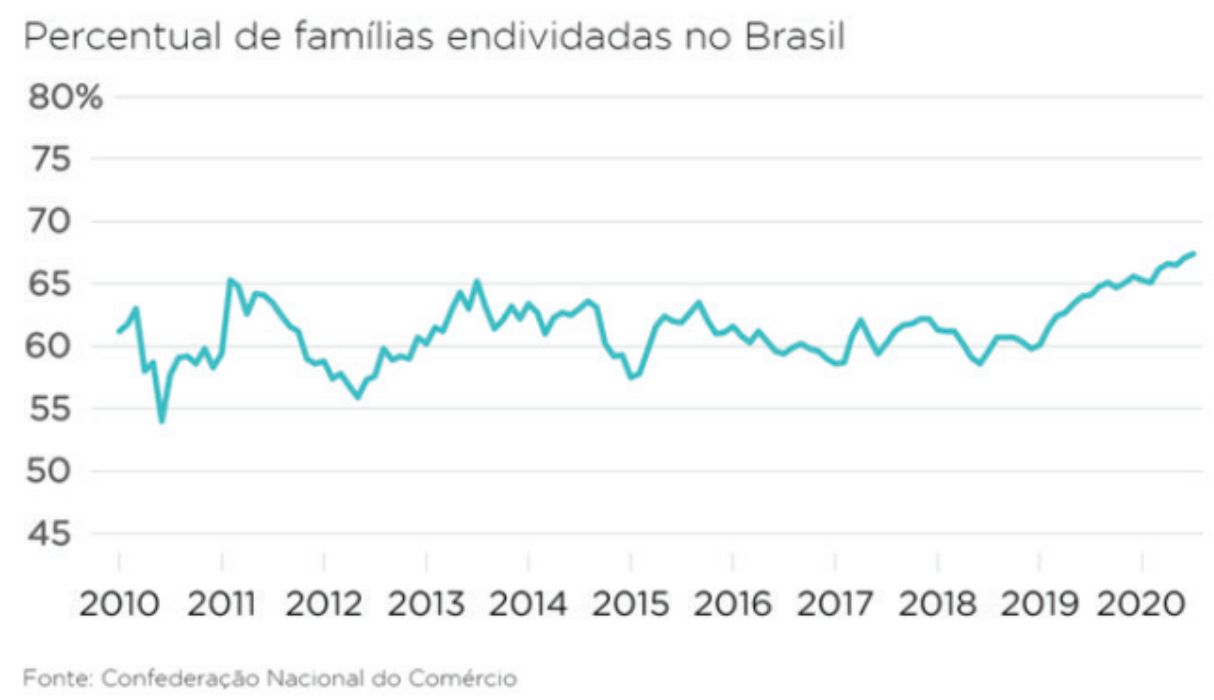

Fonte: Roubicek, 2020. 
Em fevereiro de 2020 a mesma pesquisa indicava um nível de endividamento de $65,1 \%$ (sessenta e cinco vírgula um por cento) das famílias. Acredita-se que com o cenário que se estabeleceu desde março de 2020 no Brasil, em virtude da pandemia da COVID-19 essa taxa pode vir a aumentar ainda mais nos próximos meses.

Vale ressaltar que as dívidas têm diferentes origens como por exemplo: cartão de crédito, cheque especial, carnês de loja, prestações habitacionais, prestações de bens móveis, dentre outros.

Outro dado de grande significância e que a pesquisa do CNC apresenta é a alta da inadimplência em 2020. Apesar de não ser considerado o maior índice da história, desde que a pesquisa iniciou, ela demonstra uma tendência de alta. Em dado momento as respostas das famílias indicam também que $12 \%$ (doze por cento) das mesmas estão com contas em atraso e não terão condições de honrar com seus compromissos.

\section{Gráfico 2}

\section{INADIMPLÊNCIA EM ALTA}

\section{Familias inadimplentes no Brasil \\ - Contas em atraso \\ - Não terão condição de pagar contas em atraso}

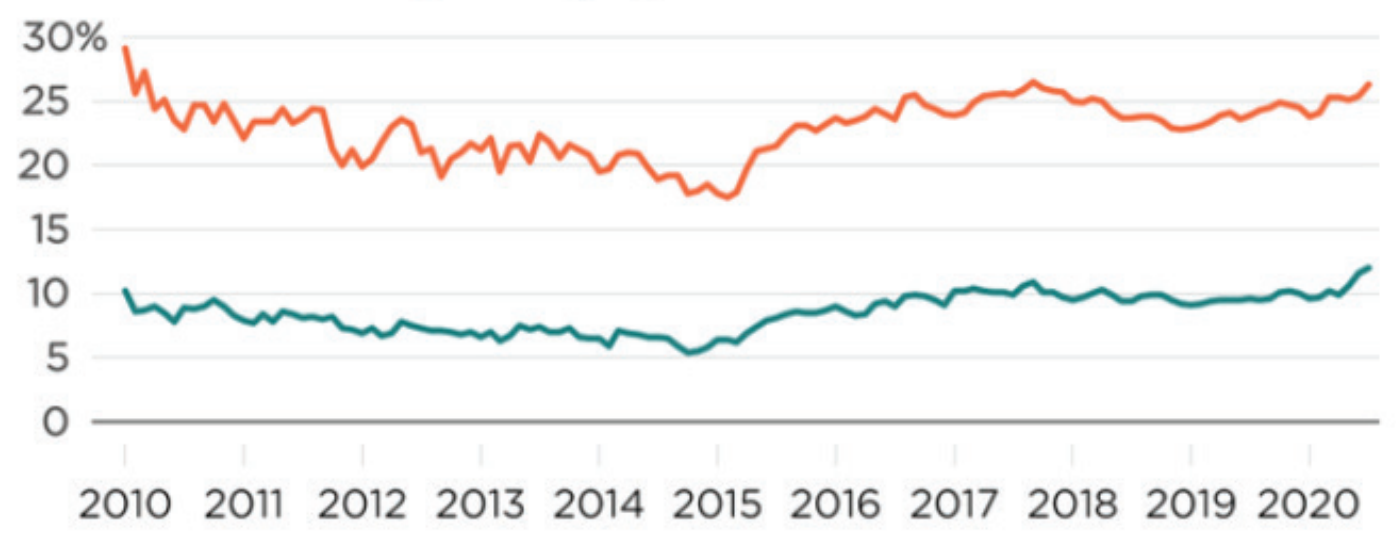

Fonte: Confederaçåo Nacional do Comércio

Fonte: Roubicek, 2020.

Entre os vários modelos de dívida a mais significativa levantada na pesquisa foi referente ao cartão de crédito que se destacou com $76,2 \%$ (setenta e seis vírgula dois por cento). Seguido das dívidas contraídas em carnê e financiamento de carro.

A modalidade de dívida através de cartão de crédito é preocupante, pois os juros dos são muito altos chegando a taxas acima de $250 \%$ (duzentos e cinquenta por cento) ao ano. 
Gráfico 3

\section{ORIGEM DAS DÍVIDAS}

Tipo de divida das familias

\section{Julho de 2020}

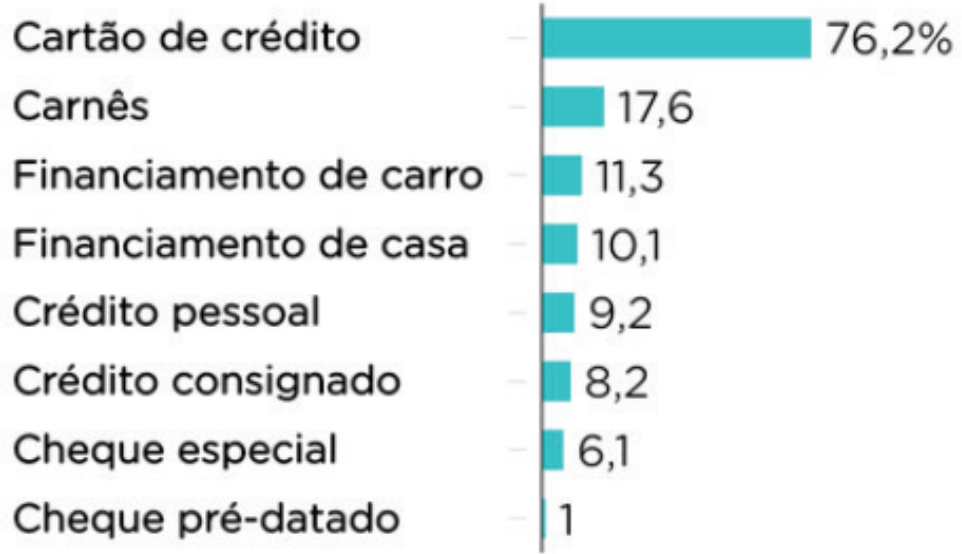

Fonte: Confederaçăo Nacional do Comércio

Fonte: Roubicek, 2020.

A pesquisa feita pela CNC também considerou na análise dos dados as famílias com recebimentos de até 10 (dez) salários-mínimos e as que perceberam acima desse patamar.

$\mathrm{Na}$ análise do mês de julho de 2020, observou-se um cenário de contraste entre as duas faixas de famílias pesquisadas. As famílias que receberam acima do teto de 10 (dez) salários-mínimos e ainda em plena situação da pandemia, demonstraram uma tendência de queda no endividamento durante a pesquisa. No entanto, houve um movimento oposto na faixa das famílias que receberam até 10 (dez) salários-mínimos onde notou-se percebido um aumento do endividamento.

Gráfico 4

\section{MOVIMENTOS OPOSTOS}

\section{Familias endividadas no Brasil, por faixa de renda}

\section{- Abaixo de 10 S.M. acima de 10 S.M.}

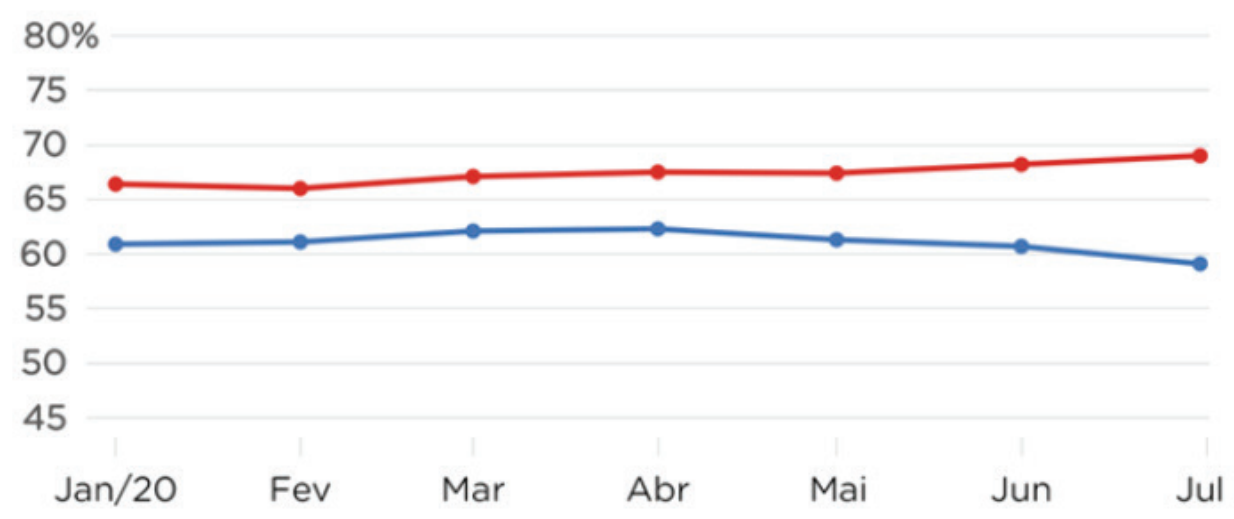

Fonte: Confederaçăo Nacional do Comércio

Fonte: Roubicek, 2020. 
Isso é corroborado com a indicação de que as famílias com renda abaixo de 10 (dez) salários-mínimos têm o cartão de crédito como principal fonte de endividamento que corresponde a $78,5 \%$ (setenta e oito vírgula cinco por cento) do total. Esse elevado grau de endividamento gera impactos negativos na economia da sociedade, com repercussões negativas na dignidade dessas pessoas.

\section{A PANDEMIA PELA COVID - 19}

O ser humano está diante de uma realidade diferenciada dos séculos passados. A globalização é um fenômeno que mudou o comportamento, quer seja da sociedade, quer seja da economia. Distâncias foram encurtadas e a tecnologia, bem como o desenvolvimento, aproximaram as pessoas de países diferentes.

Esse encurtamento das distâncias é fonte de benefícios, mas é também uma realidade que traz preocupação, pois as doenças de disseminação rápida como as doenças de origens virais caso da MERS (Middle East Respiratory Syndrome - Síndrome respiratória do Oriente Médio e Síndrome Respiratória Aguda Grave) e da SARS traz uma situação de difícil controle nesse cenário globalizado (ORGANIZAÇÃO PAN-AMERICANA DE SAÚDE, 2020).

Em 2019, surgiu uma dessas doenças virais na China, cuja característica era a facilidade de contágio, resistência do vírus no ambiente e tempo de encubação elevado (SANARMED, 2020). No início do ano de 2020, já havia relatos de incidência da COVID-19 em praticamente todos os países. Isto fez com que a Organização Mundial de Saúde decretasse, em 30 de janeiro de 2020, a COVID-19 como estado de emergência de preocupação internacional e, em seguida, no dia 11 de março de 2020 passou a designá-la como pandemia (FUNDAÇÃo OSWALDO CRUZ, 2020).

O conceito de pandemia é utilizado quando uma epidemia, que é uma doença que tem a sua disseminação restrita a um espaço limitado, acaba se espalhando por vários continentes atingindo grandes proporções e seu contágio é sustentado de pessoa a pessoa (FUNDAÇÃO OSWALDO CRUZ, 2020).

O Termo Corona Vírus (CoV) é o nome que se dá a uma família viral que possui uma estrutura em formato de coroa. Este grupo de vírus são zoonóticos, pois sua transmissão ocorre de animais para pessoas. Tais vírus podem causar doenças respiratórias leves e moderadas, com sintomas muito parecidos com a gripe comum (SANAMED, 2020).

Algumas cepas de Corona Vírus podem provocar síndromes respiratórias graves que são comumente chamadas de SARS (severe acute respiratory syndrome). Com relatos em seres humanos feitos na China em 2002 (SANAMED, 2020). Segundo o Ministério da Saúde (2020) a COVID-19 é uma doença causada pelo Corona Vírus, denominada SARS-CoV-2, cujo expecto clínico varia de infecções assintomáticas a quadro graves.

O Poder Legislativo, por meio do Decreto Legislativo de 20 de março de 2020, reconheceu o estado de calamidade pública requerido pelo Poder Executivo e em 6 de fevereiro foi aprovado o Projeto de Lei $n^{\circ} 3.160$, de 2020, prevendo a alteração da Lei $n^{\circ} 13.979$, estabe- 
lecendo as regras para tratativa deste enfrentamento, incluindo medidas como isolamento e quarentena (BRASIL, 2020).

\section{O CENÁRIO TRAZIDO PELA COVID 19 E O PROJETO DE LEI 1.166 DE 2020}

O mundo está vivendo um momento de exceção desde a pandemia da COVID-19. Conforme já analisado anteriormente, o nível de endividamento das famílias brasileiras já vinha aumentando e o consumidor se via a mercê de buscar o crédito rápido para honrar suas obrigações. Esse tipo de crédito apresenta uma faceta positiva, que é o crédito ou financiamento feito automaticamente e outra negativa que são os juros elevados.

O Poder Executivo em todas as esferas de governo tomou medidas de enfrentamento dessa calamidade para que ela impactasse o mínimo possível na condição de saúde e de vida dos brasileiros. No aspecto econômico, as consequências da pandemia também foram significativas.

Há expectativa que durante a crise e posteriormente a ela a maioria dos consumidores não tenham condições de pagar a totalidade do cartão de crédito buscando no crédito rotativo e no cheque especial uma opção para honrar suas obrigações (APROVADO..., 2020).

O ordenamento jurídico brasileiro estava contextualizado em um outro cenário antes da crise da pandemia. Isso fez com que o Poder Legislativo se sentisse pressionado na busca de atualizar a legislação do país para este momento. Atualmente, existem projetos de lei tramitando tanto no Senado, quanto na Câmara dos Deputados, dentre eles pode-se citar o Projeto de Lei 1.166/2020, que versa sobre uma variável de grande impacto no endividamento das pessoas.

Trata-se de Projeto de Lei de autoria do Senador Álvaro Dias, que propõe em sua redação original teto de juros de $20 \%$ (vinte por cento) ao ano para todas as modalidades de crédito ofertadas por meio de cartões de crédito e cheque especial entre os meses de março de 2020 a julho de 2021, cuja fiscalização caberá ao Banco Central e o descumprimento do teto, configurará crime de usura. (BRASIL, 2020).

O senador esclareceu que a sua proposta se baseia no fato de que durante a crise a perda de renda motivada, quer seja pela mudança na legislação trabalhista ou pelo desemprego, fará com que parte significativa da população busque no cartão de crédito ou no cheque especial um complemento para financiar gastos essenciais.

O autor destacou que uma taxa de $20 \%$ (vinte por cento) ao ano é satisfatória e suficiente para remunerar as instituições de crédito nesse período de crise. Para não se correr o risco de a instituição reduzir o limite de crédito, excepcionalmente durante este período, não será permitida a redução do limite nas modalidades de cheque especial e do cartão de crédito. 
O texto aprovado em agosto de 2020, no Senado, trouxe o limite de 30\% (trinta por cento) ao ano (no caso das fintechs ${ }^{5}$, o limite foi de $35 \%$ ), proibindo a cobrança de multas e juros devido à mora na liquidação da prestação de produtos e serviços e nas operações de crédito bancário, até mesmo no cartão de crédito. Previu-se, também, que a proibição da cobrança de juros retroagirá a 20 de março de 2020.

Conforme o artigo $2^{\circ}$ do substitutivo, o objetivo do Projeto de Lei é prevenir o superendividamento. Dessa forma, não valerá para quem assumir dívidas utilizando fraude ou má-fé. Ocorre que há certa demora em sua tramitação na Câmara dos Deputados associada à sinalização do atual presidente da casa, deputado Rodrigo Maia, de que não deverá votar a proposta, por considerá-la uma interferência do Legislativo no mercado financeiro (CHRISTIAN, 2020).

De acordo com João Pedro Porto, o intervencionismo é a interferência do governo no mercado, seja nos preços, nas taxas de juros e nos lucros (PORTO, 2019). Isso ocorreu em período histórico da ditadura militar, em que se limitou a taxa de juros para todas as áreas da economia, ocasionando efeitos desastrosos, como a diminuição da concessão de crédito e aumento de outros produtos financeiros (ZANONI; IGNÁCIO; BARROS; LIMA; SOUTO; SILVA, 2018).

O Projeto de Lei contraria o entendimento de diretores e do presidente do Banco Central, de que o ideal, neste momento, seria manter os contratos bancários da forma como estão, evitando a limitação de regras já existentes e quebras contratuais (GARCIA, 2020).

A FEBRABAM (Federação Brasileira de Bancos) apoiou a necessidade de reduzir o custo do crédito, mas no seu entendimento, o tabelamento, ao invés de promover alívio financeiro, poderá agravar a crise, distorcendo a formação de preços, criando gargalos e gerando insegurança jurídica.

Caso haja a aprovação do projeto de lei, mesmo que de forma tardia, isso poderá implicar novas questões, como a judicialização de contratos e a queda na oferta do crédito, com a dupla vitimização das camadas economicamente mais vulneráveis no país.

\section{A EXPERIÊNCIA ESTRANGEIRA}

Os juros constituem a remuneração sobre o capital cedido, que é calculado em função do valor total do empréstimo, do tempo da cedência e de uma taxa. É a renda que o proprietário do capital obtém sobre o valor que emprestou (VASCONCELOS, 2019).

As taxas cobradas pelo cedente podem ser fixas ou variáveis sendo que no primeiro caso refere-se a um valor não alterado, e no segundo caso são uma combinação de indexante com uma margem ou spread (VASCONCELOS, 2019).

A imposição de limites às taxas de juros não depende especificamente da legislação interna dos países. Em relação às taxas máximas, elas podem ser rígidas ou variáveis. Nas

5 A palavra fintech é uma abreviação para financial technology (tecnologia financeira, em português). Ela refere-se a startups ou empresas que desenvolvem produtos financeiros totalmente digitais, nas quais o uso da tecnologia é o principal diferencial em relação às empresas tradicionais do setor. 
taxas máximas rígidas determina-se um percentual, e no caso das variáveis utiliza-se um índice de referência que está passível de variação.

A fixação de uma taxa limite para os juros no crédito para consumidores é feita em aproximadamente 76 (setenta e seis) países, conforme consta em estudo do Banco Mundial e citado pelo Banco Central (LIMITE, 2019). Desses 76 (setenta e seis) países, 24 (vinte e quatro) adotam uma plataforma de teto único que é aplicada em todas as taxas de juros praticada em seus mercados. 0 restante, 32 (trinta e dois) países, trabalham com tetos relativos, onde existem variados índices por tipos de créditos, valores emprestados, ou prazo de vencimento (LIMITE, 2019).

Na maioria dos países introduziu-se o limite de juros via legislação, onde em 28 (vinte e oito) estabelecem as chamadas "Lei de Usura", e em 24 (vinte e quatro) existem leis especificas de taxas de juros. Somente em nove países esses limites foram introduzidos no sistema financeiro por atos normativos do Poder Executivo como o caso do cheque especial criado por uma resolução do Conselho Monetário Nacional (LIMITE, 2019).

Através de um comparativo entre a taxa de juros do cheque especial entre o Brasil e outros países podemos visualizar a discrepância do custo entre eles, inclusive se comparados com a nova medida adotada pelo Conselho monetário Nacional em 27 do novembro de 2019 que limitou a 8\% (oito por cento) ao mês a taxa do cheque especial (GOMES, 2020).

No caso do Brasil a taxa de juros anual no cheque especial chegava até 2019 em até $305 \%$ (trezentos e cinco por cento), sendo que a partir de janeiro de 2020 ficou limitado até $151 \%$ (cento e cinquenta e um por cento). No Canadá esta taxa é de 19\% (dezenove por cento) a $22 \%$ (vinte e dois por cento). Portugal 15,7\% (quinze vírgula sete por cento). França 13,81\% (treze vírgula oitenta e um por cento). Espanha 7,5\% (sete vírgula cinco por cento). 0 que demonstra que o custo das obrigações para os consumidores brasileiros é cerca de 10 vezes o custo que os Portugueses têm que arcar no mesmo tipo de crédito ou quando comparado com os Espanhóis, 20 (vinte) vezes (GOMES, 2020).

Na modalidade mais utilizada de crédito pela família brasileira que é o cartão de crédito, o consumidor paga taxa de juros muito altas. Caso exista necessidade de se financiar as obrigações do cartão de crédito através de uma modalidade chamada rotativo, estes juros podiam chegar até mais de 350\% (trezentos e cinquenta por cento) em 2019 (O BRASILEIRO..., 2017).

Os juros do rotativo são pagos quando o consumidor faz opção de não pagamento do total da fatura do cartão, dessa forma ele adquire automaticamente um crédito com a instituição financeira. 
Gráfico 5

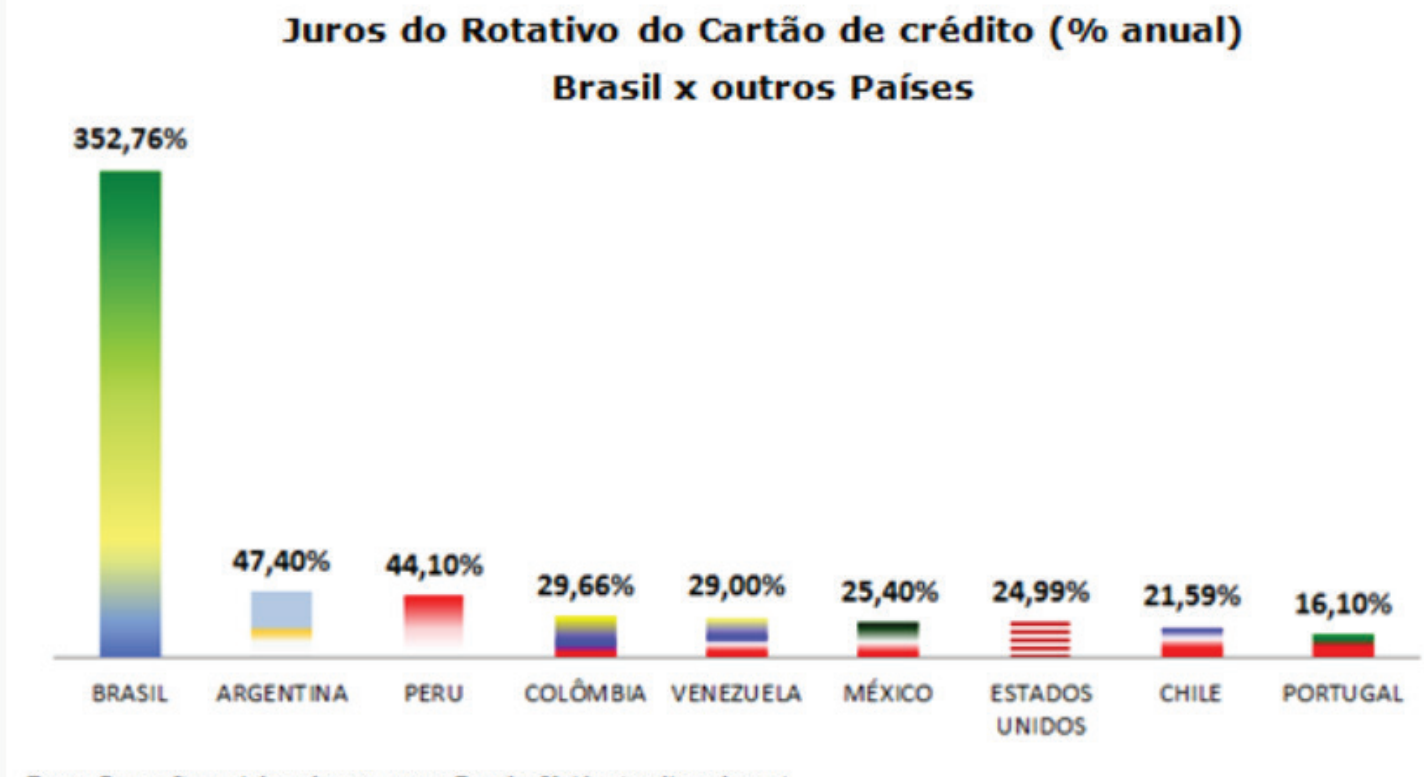

Fonte: Banco Central de cada pars exceto Estados Unilos (credixardscom).

Fonte: Roubicek, 2020.

Quando comparada a taxa média aplicada no crédito rotativo no Brasil com outros países consegue-se visualizar a grande diferença entre elas. No caso de Portugal que é uma das maiores taxas na Europa, tem juros de no máximo 16,1\% (dezesseis vírgula um por cento). Nos Estados Unidos a taxa dos consumidores que optam pelo crédito rotativo chega a no máximo a 24,99\% (vinte e quatro vírgula noventa e nove por cento).

\section{CONCLUSÃO}

O presente artigo analisou o Projeto de Lei $n^{0} 1.166$, de autoria do Senador Álvaro Dias, já aprovado em primeiro turno pelo Senado Federal (BRASIL, 2020). Por meio dele, pôde-se analisar a gravidade dos efeitos do endividamento na vida das pessoas, especialmente durante a pandemia.

A COVID-19 surgiu em um cenário de endividamento elevado, quando o governo adotou medidas de enfrentamento frente ao estado de calamidade pública que se instalou. 0 crédito passou a ser usado para demandas básicas, como aluguel, luz, água e alimentação, necessidades essenciais do cotidiano das pessoas.

Apesar de o projeto prever mecanismos que, aparentemente, pareçam adequados para mitigação do quadro de superendividamento brasileiro, a demora na sua tramitação poderá implicar novas questões, como a judicialização de contratos, a queda na oferta de crédito, com a dupla vitimização das camadas economicamente mais vulneráveis, gerando insegurança jurídica. 
Além do mais, a interferência estatal, como sugerida no projeto, poderá abrir precedentes para maior intervenção do Estado na economia, como aconteceu no período da ditadura militar, com resultados catastróficos.

Faz-se necessária, a implementação de cultura de educação financeira no país, aliada a estímulos positivos, ou seja, mediante estímulos conscientes, invisíveis e com o mínimo de custo político e econômico. Com isso, pode-se obter grandes conquistas em relação às finanças e, em especial, mitigando o superendividamento das pessoas.

\section{REFERÊNCIAS}

APROVADO projeto de Alvaro Dias que estabelece teto para juros de cheque especial e cartão. Alvaro Dias, Brasília, DF, 6 ago. 2020. Disponível em: https://alvarodias.com.br/2020/08/06/aprovado-projeto-de-alvaro-dias-que-estabelece-teto-para-juros-de-cheque-especial-e-cartao/. Acesso em: 7 out. 2020.

ÁVILA, Flávia; BIANCHI, Ana Maria. O que é? Economia Comportamental, [S. I.], [2020]. Disponível em: http://www. economiacomportamental.org/o-que-e/. Acesso em: 20 nov. 20.

BRASIL. [Constituição (1988)]. Constituição da República do Brasil de 1988. Brasília, DF: Presidência da República, [2020]. Disponível em: http://www.planalto.gov.br/ccivil_03/constituicao/constituicao.htm. Acesso em: 7 out. 2020.

BRASIL. Decreto-lei n 10.393, de 9 de junho de 2020. Institui a nova Estratégia Nacional de Educação Financeira ENEF e o Fórum Brasileiro de Educação Financeira - FBEF. Brasília, DF: Presidência da República, 2020. Disponível em: http://www.planalto.gov.br/ccivil_03/_Ato2019-2022/2020/Decreto/D10393.htm. Acesso em: 7 de out. 2020.

BRASIL. Ministério da Integração Nacional (Secretaria de Defesa Civil). Política Nacional de Defesa Civil. Brasília, DF: Ministério da Integração Nacional, 2020. Disponível em: http://www.gabinetemilitar.mg.gov.br/images/documentos/Defesa\%20Civil/manuais/Pol\%C3\%ADtica-Nacional-de-Defesa-Civil.pdf. Acesso em: 7 out. 2020.

BRASIL. Ministério da Saúde. Coronavírus COVID-19. Brasília, DF: Ministério da Saúde, 2020. Disponível em: https://coronavirus.saude.gov.br/. Acesso em: 7 out. 2020.

BRASIL. Projeto de Lei $n^{\circ} 3.160$, de 2020. Altera a Lei $n^{\circ} 13.979$, de 6 de fevereiro de 2020, que dispõe sobre as medidas para enfrentamento da emergência de saúde pública de importância internacional decorrente do coronavírus responsável pelo surto de 2019, para criar o Plano Nacional de Gestão ao Combate ao Coronavírus. Brasília, DF: Senado Federal, 2020. Disponível em: https://www25.senado.leg.br/web/atividade/materias/-/ materia/142387. Acesso em: 7 out. 2020.

BRASIL. Senado Federal. Projeto de Lei Complementar n 1.166, de 28 de fevereiro de 2020. Brasília, DF: Senado Federal, 2020. Disponível em: https://www25.senado.leg.br/web/atividade/materias/-/materia/141297. Acesso em: 7 de out. 2020.

CHRISTIAN, H. Senadores repercutem decisão de Maia de não votar limitação de juros do cartão. Senado Notícias, Brasília, DF, 21 ago. 2020. Disponível em: https://www12.senado.leg.br/noticias/audios/2020/08/senadores-repercutem-decisao-de-maia-de-nao-votar-limitacao-de-juros-do-cartao. Acesso em: 14 nov. 2020.

CONFEDERAÇÃO NACIONAL DO COMÉRCIO DE BENS, SERVIÇOS E TURISMO. Pesquisa de Intenção de Consumo das Familias (ICF) - Agosto de 2020. [S. I.]: CNC, 2020. Disponível em: http://cnc.org.br/editorias/economia/pesquisas/pesquisa-de-intencao-de-consumo-das-familias-icf-agosto-de-2020. Acesso em: 7 out. 2020.

CONFEDERAÇÃO NACIONAL DO COMÉRCIO DE BENS, SERVIÇOS E TURISMO. Pesquisa de Endividamento e Inadimplência do Consumidor (Peic) - junho de 2020. [S. I.]: CNC, 2020. Disponível em: http://cnc.org.br/editorias/economia/pesquisas/pesquisa-de-endividamento-e-inadimplencia-do-consumidor-peic-junho-0. Acesso em: 7 out. 2020. 
FANECO, Lívia Carvalho da Silva. O superenvidamento do consumidor: análise das decisões do Superior Tribunal de Justiça acerca do contrato de cartão de crédito. 2016. Dissertação (Mestrado em Direito) - Programa de Pós-Graduação Stricto Sensu em Direito. Universidade de São Paulo. São Paulo, 2016. Disponível em: https://teses. usp.br/teses/disponiveis/107/107131/tde-01092017-080249/publico/LiviaCSFanecoOriginal.pdf. Acesso em: 20 nov. 2020.

FUNDAÇÃO OSWALDO CRUZ. Notícias e Artigos: O que é Pandemia? Rio de Janeiro: Fiocruz, 2020. Disponível em: https://www.bio.fiocruz.br/index.php/br/noticias/1763-o-que-e-uma-pandemia. Acesso em: 7 out. 2020.

GOMES, Luiz Flávio. Juros de 8\% (cheque especial): os bancos vão lucrar com isso? Conteúdo Jurídico, [S. I.], 6 set. 2020. Disponível em: https://conteudojuridico.com.br/coluna/3008/juros-de-8-cheque-especial-os-bancos-vo-lucrar-com-isso. Acesso em: 7 out. 2020.

JUROS tabelados elevariam pressão sobre rentabilidade de bancos. Agência CMA, [S. I.], 10 set. 2020. Disponível em: https://www.agenciacma.com.br/juros-tabelados-elevariam-pressao-sobre-rentabilidade-de-bancos/. Acesso em: 20 nov. 2020.

LIMITE para juros de cheque especial existe em 76 países. Dom Total, [S. I.], 3 dez. 2019. Disponível em: https:// domtotal.com/noticia/1406780/2019/12/limite-para-juros-de-cheque-especial-existe-em-76-paises/. Acesso em: 7 out. 2020 .

O BRASILEIRO paga os maiores juros do mundo. [S. I.]: Proteste, 2017. Disponível em: https://www.proteste.org. br/dinheiro/cartao-de-credito/noticia/brasileiro-paga-os-maiores-juros-do-mundo. Acesso em: 7 out. 2020.

ORGANIZAÇÃO PAN-AMERICADA DE SAÚDE. Folha informativa COVID-19 - Escritório da OPAS e da OMS no Brasil. [S. I.]: OPAS, 2020. Disponível em: https://www.paho.org/pt/covid19. Acesso em: 7 out. 2020.

PORTO, João Pedro. O intervencionismo do Estado na economia. In: ETIC-ENCONTRO DE INICIAÇÃO CIENTíFICA. Anais [...]. Toledo: ETIC, 2019. Disponível em: http://intertemas.toledoprudente.edu.br/index.php/ETIC/article/ view/7996. Acesso em: 14 nov. 2020.

RESUMOS: síndrome respiratória aguda grave (SARS). [S. I.]: Sanarmed, 2020. Disponível em: https://www.sanarmed.com/resumos-sindrome-respiratoria-aguda-grave-sars-ligas. Acesso em: 7 out. 2020.

RIBEIRO, Marcia Carla Pereira; DOMINGUES, Victor Hugo. Economia comportamental e direito: a racionalidade em mudança. Revista Brasileira de Políticas Públicas, [S. I.], v. 8, n. 2, p. 456-471, 2018.

ROUBICEK, Marcelo. A inadimplência na pandemia. E os impactos na economia. Nexo Jornal, [S. I.], 3 ago. 2020. Disponível em: https://www.nexojornal.com.br/expresso/2020/08/03/A-inadimpl\%C3\%AAncia-na-pandemia.-E-os-impactos-para-a-economia. Acesso em: 7 out. 2020.

TABELAR juros e elevar taxação de bancos prejudicam a economia, diz diretor do BC. Folha de São Paulo, [S. I.], 22 maio 2020. Disponível em: https://www1.folha.uol.com.br/mercado/2020/05/tabelar-juros-e-elevar-taxacao-de-bancos-sao-medidas-deleterias-para-economia-diz-diretor-do-bc.shtml. Acesso em: 20 nov. 2020.

THALER, Richard H.; SUNSTEIN, Cass R.. Nudge: como tomar melhores decisões sobre saúde, dinheiro e felicidade. Rio de Janeiro: Schwarcz, 2019.

VASCONCELOS, Miguel Pestana. De novo os limites máximos das taxas de juro das instituições de crédito e das sociedades financeiras. Revista de Direito Comercial, [S. I.], 2019. Disponível em: https://static1.squarespace. com/static/58596f8a29687fe710cf45cd/t/5d72610d8cb59266acd27831/1567777039890/2019-17.pdf. Acesso em: 7 out. 2020 .

ZANONI; Lucas; IGNÁCIO, Frederico; BARROS, Bruno; LIMA, Diego; SOUTO, Augusto; SILVA, Júlio. Economia e Desigualdade na Ditadura Militar: relatório final do trabalho apresentado à disciplina História do Brasil Independente. Universidade Federal de São Paulo, São Paulo, 2018.

Recebido/Received: 30.04.2020.

Aprovado/Approved: 25.11.2020. 